\title{
SISTEM INFORMASI PENJUALAN KONVEKSI DI TOKO MAKMUR 2 TEMBILAHAN
}

\author{
${ }^{1}$ Bayu Rianto, ${ }^{2}$ Rino \\ 1,2 Sistem Informasi, Fakultas Teknik dan Ilmu Komputer, Universitas Islam Indraigiri, \\ Jl. Propinsi No.1 Kec.Tembilahan, Kab. Indraigiri Hilir, Prov. Riau \\ Email: ${ }^{1}$ rianto.bayu@gmail.com ,2rinomild2@gmail.com
}

\begin{abstract}
Today's technology has touched various aspects of people's lives such as education, health, administration, business and others. One of the most widely used technology uses today is the sales system, online-based sales have been very much done by the public, only by accessing E-Commerce via the Internet alone, buyers can choose the desired items, find out the details of the goods, and can make transactions with whom alone without being limited by time and distance. The purpose of this study is to analyze the problems that exist in Toko Makmur 2 Tembilahan namely the absence of online sales media, frequent sales reporting errors and inventory management are still manual. The purpose of this study is to apply the E-Commerce Website at the Makmur 2 Tembilahan store that can overcome the reporting errors and management of merchandise stock. The research methodology used is Observation, Literature, Interview and Analysis. The results in this study are the implementation of an online-based sales system that can help the problems that have occurred in Toko Makmur 2 Tembilahan which is serving online-based sales, sales reports can be quickly and easily and inventory management is also easier.
\end{abstract}

Keywords-E-Commerce, Information System, Sale, Website

Abstrak-Teknologi saat ini telah menyentuh berbagai aspek kehidupan masyarakat seperti pendidikan, kesehatan, administrasi, bisnis dan lain-lain. Salah satu pemanfaatan teknologi yang banyak digunakan saat ini adalah sistem penjualan, penjualan berbasis online sudah sangat banyak dilakukan oleh masyarakat, hanya dengan mengakses E-Commerce melalui Internet saja, pembeli dapat memilih barang yang diinginkan, mengetahui rincian barang, dan dapat melakukan transaksi dengan siapa saja tanpa dibatasi oleh waktu dan jarak. Tujuan dari penelitian ini adalah untuk menganalisis masalah-masalah yang ada di Toko Makmur 2 Tembilahan yaitu belum adanya media penjualan online, sering terjadi kesalahan pelaporan penjualan dan pengelolaan stok barang masih manual. Tujuan dari penelitian ini adalah menerapkan Website E-Commerce pada toko Makmur 2 Tembilahan yang dapat menanggulangi kesalahan pelaporan dan pengelolaan stok barang dagangan. Metodologi penelitian yang digunakan adalah Observasi, Kepustakaan, Wawancara dan Analisis. Hasil dalam penelitian ini adalah dengan diimplementasikannya sistem penjualan berbasis online dapat membantu permasalahan yang selama ini terjadi pada Toko Makmur 2 Tembilahan yaitu melayani penjualan berbasis online, laporan penjualan dapat dengan cepat dan mudah serta pengelolaan stok barang juga lebih mudah.

Kata kunci- E-Commerce, Sistem Informasi, Penjualan, Website

\section{PENDAHULUAN}

Sarana internet adalah salah satu media informasi yang efektif dan efisien dalam penyampaian informasi yang dapat pula diakses oleh setiap orang dimana saja dan kapan saja. Media internet sangat berpengaruh dalam dunia bisnis dan perdagangan. Selain itu teknologi internet sudah tidak asing bagi beberapa pengusaha dan pelaku bisnis. Saat ini para pengusaha sudah banyak yang memanfaatkan media internet sebagai sarana penjualan barang, hal tersebut dilakukan semata-mata untuk meningkatkan omset penjualan mereka, mengingat dunia maya tidak mengenal batasan ruang dan waktu.

Trend jual beli online ini tidak terlepas dari perkembangan pengguna Internet di Dunia, kini internet bukan hal yang asing lagi bagi masyarakat termasuk di Indonesia sendiri, bahkan banyak masyarakat yang hidup dengan ketergantungan akan internet. Oleh karena itu peluang ini banyak digunakan oleh para pengusaha atau pedagang untuk memasarkan barang dangannya melalui media Internet yang dianggap lebih relevan dan efesien serta dapat menjangkau seluruh masyarakat di dunia yang tentu diharapkan akan meningkatkan penjualan.

Jual Beli di Internet atau perdagangan Elektronik biasa disebut E-commerce adalah penyebaran, pembelian, penjualan, pemasaran barang dan jasa melalui internet atau jaringan komputer. Seluruh komponen yang ada dalam perdagangan diaplikasikan ke dalam e-commerce seperti layanan produk, cara pembayaran dan cara 1 | http://www.jurnal.umb.ac.id/index.php/JTIS 
promosi. Perkembangan internet yang semakin maju merupakan salah satu faktor pendorong berkembangnya e-commerce. Internet merupakan salah satu jaringan global yang menghubungkan jaringan komputer diseluruh dunia, sehingga memungkinkan terjalinnya komunikasi dan interaksi antar satu perusahaan dengan konsumen.

Toko Makmur 2 Tembilahan yang terletak di Jalan Jendral Sudirman bergerak dibidang penjualan alat-alat konveksi ingin memanfaatkan perkembangan teknologi dan mengikuti trend yang kini telah berkembang di kalangan pebisnis yaitu sistem jual beli online, dengan sistem ini diharapkan toko Makmur 2 Tembilahan yang semula tergolong usaha kecil dan masih memiliki konsumen yang sangat terbatas diharapkan dapat terus berkembang dan bersaing serta meningkatkan penjualan dan memperluas pangsa pasar. Kendala lain yang di alami yaitu persaingan yang ketat, hal itu membuat Toko Makmur 2 Tembilahan harus mempunyai strategi penjualan yang berbeda dari pesaingnya. Untuk itu dibutuhkan sebuah sistem pelayanan jual beli secara online berupa website.

\section{LANDASAN TEORI}

A. Konsep Dasar Sistem

Sistem didefenisikan sebagai sekumpulan prosedur yang saling berkaitan dan saling terhubung untuk melakukan suatu tugas bersamasama. Secara garis besar, sebuah sistem informasi terdiri atas tiga komponen utama. Ketiga komponen tersebut mencakup software, hardware, dan brainware ketiga komponen ini saling berkaitan satu sama lain. Software mencakup semua perangkat lunak yang dibangun dengan bahasa pemrograman tertentu, pustaka, untuk kemudian menjadi sistem operasi, aplikasi, dan driver. Sistem operasi, aplikasi, driver, saling bekerja sama agar komputer dapat berjalan dengan baik. Hardware mencakup semua perangkat keras (motherboard, processor, VGA dan lainnya) yang disatukan menjadi sebuah komputer. Dalam konteks yang luas, bukan hanya sebuah komputer, namun sebuah jaringan komputer. Brainware mencakup kemampuan otak manusia, yang mencakup ide, pemikiran, analisis, di dalam menciptakan dan menggabungkan hardware dan software. Penggabungan software dan hardware dengan bantuan brainware inilah (melalui sejumlah prosedur) yang dapat menciptakan sebuah sistem yang bermanfaat bagi pengguna ${ }^{2}$.

\section{B. Konsep Dasar Informasi}

Informasi merupakan hasil pengolahan data dari satu atau berbagai sumber, yang kemudian diolah, sehingga memberikan nilai, arti, dan manfaat. Proses pengolahan ini memerlukan teknologi. Berbicara mengenai teknologi memang tidak harus selalu berkaitan dengan komputer, namun komputer sendiri merupakan salah satu bentuk teknologi. Dengan kata lain, alat tulis dan mesin ketikpun dapat dimasukkan sebagai salah satu bentuk teknologi. Pada proses pengolahan data, Untuk dapat menghasilkan informasi, juga dilakukan proses verifikasi secara akurat, spesifik, dan tepat waktu. Hal ini penting agar informasi dapat memberikan nilai dan pemahaman kepada pengguna. Pengguna dalam hal ini mencakup pembaca, pendengar, penonton, bergantung pada bagaimana cara pengguna tersebut menikmati sajian informasi dan melalui media apa informasi tersebut disajikan ${ }^{2}$.

\section{Konsep Dasar Sistem Informasi}

Sistem Informasi merupakan gabungan dari empat bagian utama. Keempat bagian utama tersebut mencakup perangkat lunak (software), perangkat keras (hardware), infrastruktur, dan Sumber Daya Manusia (SDM) yang terlatih. Keempat bagian utama ini saling berkaitan untuk menciptakan sebuah sistem yang dapat mengolah data menjadi informasi yang bermanfaat. Di dalamnya juga termasuk proses perencanaan, kontrol, koordinasi, dan pengambilan keputusan. Sehingga, sebagai sebuah sistem yang mengolah data menjadi informasi yang akan disajikan dan digunakan oleh pengguna, maka sistem informasi merupakan sebuah sistem yang kompleks. Bukan hanya komputer saja yang berkerja (beserta Software dan hardware di dalamnya), namun juga manusia (dengan brainware yang dimiliki). Manusia (pengguna/aktor) dalam hal ini menggunakan seluruh ide, pemikiran, perhitungan, untuk dituangkan ke dalam sistem informasi yang digunakan ${ }^{2}$

\section{Penjualan dan E-Commerce}

Sedangkan Moekijat (2000), Penjualan (selling) adalah suatu kegiatan yang ditujukan untuk mencari pembeli, mempengaruhi, dan memberi petunjuk agar pembeli dapat menyesuaikan kebutuhannya dengan produksi yang ditawarkan serta mengadakan perjanjian mengenai harga yang menguntungkan bagi kedua pihak ${ }^{5}$.

\section{E. Internet}

Menurut Sidharta (1996) Internet adalah singkatan dari Interconnected Network. Internet merupakan sebuah sistem komunikasi yang mampu menghubungkan jaringan-jaringan computer diseluruh dunia. Internet adalah interkoneksi antar jaringan komputer namun secara umumInternet harus dipandang sebagai sumber daya informasi. Isi Internet adalah informasi, dapat dibayangkan sebagai suatu database atau perpustakaan 
multimediayang sangat besar dan lengkap. Bahkan Internet dipandang sebagai dunia dalambentuk lain (maya) karena hampir seluruh aspek kehidupan di dunia nyata ada diInternet seperti bisnis, hiburan, olah raga, politik dan lain sebagainya ${ }^{1}$.

F. Website

Website atau situs dapat diartikan sebagai kumpulan halaman halaman yang digunakan untuk menampilkan informasi, teks, gambar diam atau bergerak, animasi, suara, dan atau gabungan dari semuanya itu, baik yang bersifat statis maupun dinamis yang membentuk satu rangkaian bangunan yang saling berkait dimana masing-masing dihubungkan dengan jaringan jaringan halama ${ }^{4}$.

\section{G. HTML}

Menurut Raharjo (2011) "HTML adalah singkatan dari HyperText Markup Language, yaitu bahasa (aturan) standar yang digunakan untuk menampilkan teks, gambar, video atau audio ke dalam halaman web". Bahasa HTML merupakan bahasa yang digunakan untuk membuat halaman website dengan menggunakan tag-tag yang telah dideklarasikan pada halaman notepad dan dapat saling berhubungan dengan dokumen HTML lainnya atau yang sering disebut dengan istilah link $^{3}$.

\section{H. PHP}

PHP adalah singkatan dari Hypertext Preprocessor yang digunakan sebagai bahasa script server-side dalam pengembangan web yang disisipkan pada dokumen HTML. Pengguna PHP memungkinkan web dapat dibuat dinamis sehingga maintenance situs web tersebut menjadi lebih mudah dan efisien. PHP merupakan software open source yang disebarkan dan dilisensikan secara gratis.

\section{Web Browser}

Menurut Sibero (2013) “Web Browser adalah aplikasi perangkat lunak yang digunakan untuk mengambil dan menyajikan sumber informasi web"3.

\section{METODE PENELITIAN}

Untuk mendapatkan informasi dan data-data yang diperlukan yaitu menggunakan teknik sebagai berikut: (1) Observasi, Adalah pengamatan langsung yang dilakukan oleh peneliti dari sistem penjualan pada Toko Makmur 2 Tembilahan dengan tujuan mencari dan mengumpulkan data yang diperlukan serta mengamati apa yang menjadi titik kelemahan atau kekurangan dari sistem yang sedang berjalan sehingga peneliti dapat membantu memberikan jalan keluar dalam memperbaiki sistem tersebut. (2) Wawancara, Penulis menanyakan langsung kepada pemilik Toko
Makmur 2 Tembilahan untuk mendapatkan beberapa informasi yang dibutuhkan, mulai dari sistem penjualan, sistem pendataan barang dagangan dan pencatatan transaksi penjualan serta kendala-kendala yang dihadapi dalam proses penjualan tersebut. (3) Studi Literature, Penulis mencari informasi melalui berbagai macam bukubuku dan jurnal dan berbagai macam sumber lainnya yang berguna bagi penulisan tugas akhir ini.

A. Metode Pengembangan Sistem

Untuk mengembangkan Website Penjualan ini penulis menggunakan metode pengembangan sistem SDLC (System Development Life Cycle). Adapun tahapan-tahapan dari SDLC adalah sebagai berikut:

1. Analisis

Tahapan analisis digunakan oleh analisis sistem untuk membuat keputusan. Apabila sistem saat ini mempunyai masalah atau sudah tidak berfungsi secara baik, dan hasil analisisnya digunakan sebagai dasar untuk memperbaiki sistem. Seorang analisis perlu mengetahui ruang lingkup perkerjaan yang ditanganinya, perlu memahami sistem yang sedang berjalan saat ini, dan dapat melakukan identifikasi terhadap masalah yang muncul dan mencari solusinya dengan professional.

2. Perancangan/Desain

Tahapan perancangan (design) memiliki tujuan untuk mendesign sistem baru yang dapat menyelesaikan masalah-masalah yang dihadapi perusahaan yang diperoleh dari pemilihan alternatif sistem yang terbaik. Kegiatan yang dilakukan dalam tahap perencangan ini meliputi perancangan output, input, file.

3. Perancangan Keluaran

Perancangan Keluaran bertujuan menentukan keluaran-keluaran yang akan digunakan oleh sistem. keluaran tersebut berupa tampilan-tampilan layar, dan juga format dan frekuensi laporan yang diperlukan.

4. Perancangan Masukan

Perancangan masukan bertujuan menentukan data-data masukan, yang akan digunakan untuk mengoperasikan sistem.

5. Perancangan File

Perancangan File masuk dalam bahagian perancangan basis data, yang diawali dengan merancang diagram hubungan antara entitas (bisa dengan menggunakan ERD (bisa menggunakan ERD versi Chen atau versi James Martin). Setelah itu melakukan uji normalisasi dari 1-NF sampai ke 
5-NF, minimal sampai ke bentuk normalisasi ke-3 (3-NF).

\section{Implementation}

Tahap implementation memiliki beberapa tujuan, yaitu untuk melakukan kegiatan spesifikasi perancangan logical ke dalam kegiatan yang sebenarnya dari sistem Informasi yang akan dibangunnya atau dikembangkannya, lalu mengimplementasikan sistem yang baru tersebut ke dalam salah satu bahasa pemrograman yang paling sesuai.

\section{Programming \& Testing}

Pada tahap ini dilakukan perancangan algoritma dengan menggunakan pseudocode yang ditulis dalam bahasa Indonesia terstruktur atau bahasa Inggris terstruktur. Perancangan algoritma sebaiknya dilakukan dengan menggunakan penketatan top-down (pemrograman modular). Setelah selesai pembuatan algoritma, maka dibuatkanlah program aplikasi dengan menggunakan salah satu bahasa pemrograman terpilih.

8. Training

End User yang akan mengoperasikan sistem yang baru tersebut perlu dilatih secara keseluruhan.

\section{System Changeover}

Setelah seluruh sistem siap dioperasikan dan seluruh end user selesai dilatih, maka pada tahap ini dilakukan pergantian sistem yang lama dengan sistem yang baru. Teknik pergantiannya bisa secara perlahan/bertahap atau secara keseluruhan.

\section{HASIL DAN PEMBAHASAN}

Hasil dari penelitian ini adalah menerapkan sistem Informasi Penjualan pada Toko Makmur 2 Tembilahan sehingga dapat memecahkan beberapa permasalah yang selama ini dihadapi. Berikut ini adalah penerapan dari sistem informasi penjualan pada Toko Makmur 2 Tembilahan.

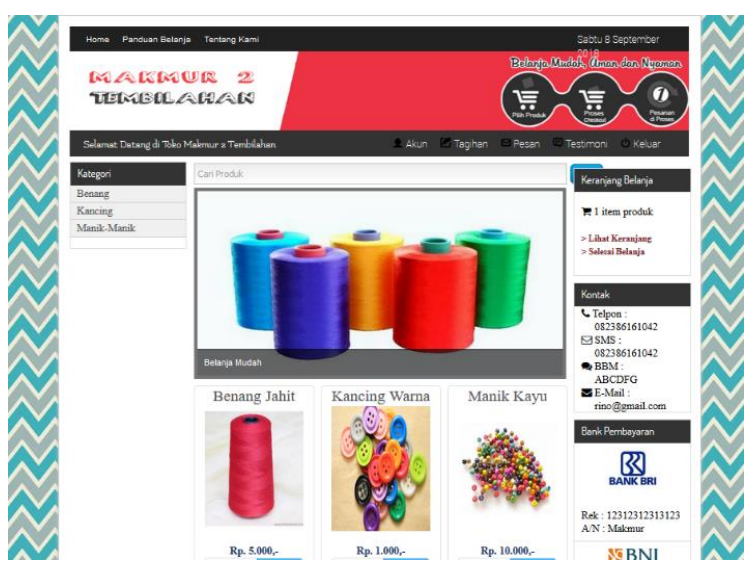

Gbr 1 Menu Utama

Gambar 1 adalah menu utama pada website penjualan pada Toko Makmur 2 Tembilahan, dimana terdapat daftar produk-produk baru yang dijual, kategori produk, dan menu-menu lainnya pada website.

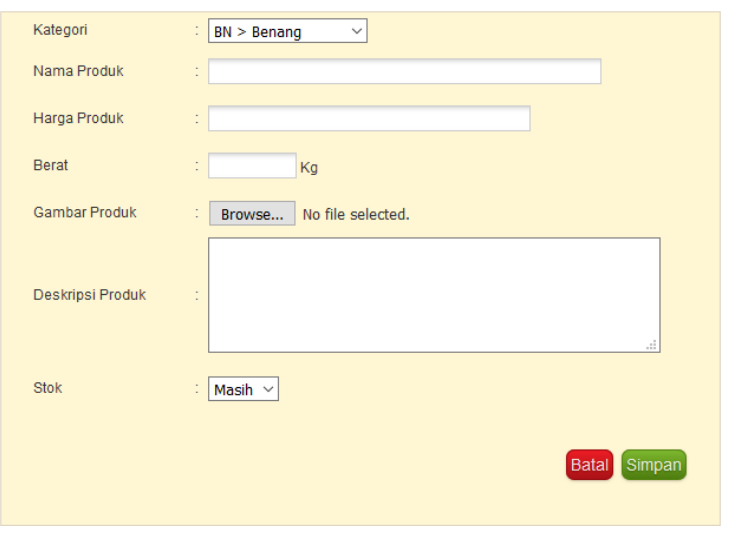

Gbr 2 Input Data Produk

Gambar 2 adalah menu untuk melakukan input data Produk, data-data yang di input antara lain adalah nama Produk, kategori Produk, harga, berat, gambar, dan stok barang.

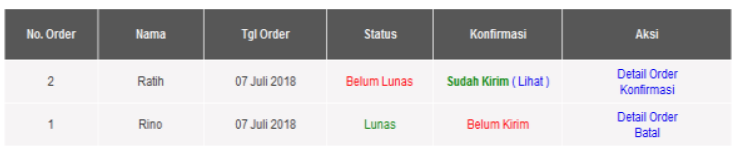

Gbr 3 Pesanan Masuk

Gambar 3 adalah tampilan data pesanan masuk yang dilakukan oleh member yang melakukan pemesanan alat konveksi secara online, data yang ditampilkan antara lain adalah nama pemesan, tanggal pemesanan, alamat dan status pemesanan. Pada halaman ini juga dapat melihat data pesanan lebih detail sesuai data yang dipilih oleh admin. 


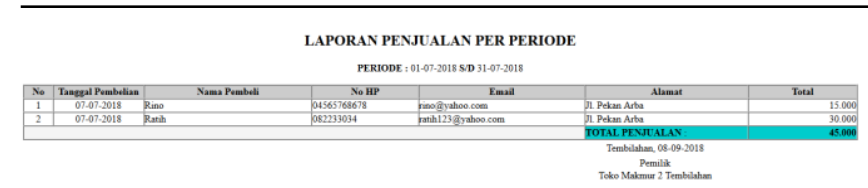

Gbr 4 Laporan Data Barang

Gambar 4 adalah tampilan laporan data penjualan perperiode yang siap dicetak dan dilaporkan kepada pemilik sehingga pelaporan penjualan dapat dengan mudah dibuat karena setiap transaksi dapat tercatat otomatis oleh sistem.

\section{KESIMPULAN DAN SARAN}

Berdasarkan hasil temuan masalah yang ada dilapangan bahwa Toko Makmur 2 Tembilahan mengalami kendala dalam mengelola produk, dan pencetakan laporan serta belum bisa melayani pembelian secara online sehingga dengan menerapkan website Penjualan pada Toko Makmur 2 Tembilahan ini dapat menanggulangi permasalahan yang selama ini dihadapi.

\section{Referensi}

[1] Hendrianto, D. E. (2014). Pembuatan Sistem Informasi Perpustakaan Berbasis Website Pada Sekolah Menegah Pertama Negeri 1 Donorojo Kabupaten Pacitan. Indonesian Juournal on Networking Security, 3(4), 5764.

[2] Pratama, I. P. (2014). Sistem Informasi dan Implementasinya. Bandung: Informatika.

[3] Supriyanta, \& Nisa, K. (2015). Perancangan Website Desa Wisata Karangrejo Sebagai Media Informasi dan Promosi. Bianglala Informatika, 3(1), 35-40.

[4] Utama, Y. (2011). Sistem Informasi Berbasis Web Jurusan Sistem Informasi Fakultas Ilmu Komputer Universitas Sriwijaya. Sistem Informasi, 3(2), 359-370.

[5] Wahana, A., \& Riswaya, A. R. (2014). Perancangan Aplikasi Pengolahan Data Report Penjualan. Jurnal Computech \& Bisnis, 8(1), 25.

[6] Wyzer, M., Durachman, Y., \& Arifin, V. (2011). Aplikasi Penjualan Produk Alat Musik Berbasis Web ( Studi Kasus PT . Duta Karya Musikindo Jakarta ). Sistem Informasi, 4(1), 1-7. 